\title{
EDUCAÇÃO AMBIENTAL NO ENSINO PÚBLICO FORMAL E A SENSIBILIZAÇÃO PARA O VALOR E IMPORTÂNCIA DA ÁGUA
}

\author{
Environmental education in the formal public education and awareness of the value and \\ importance of water ${ }^{1}$

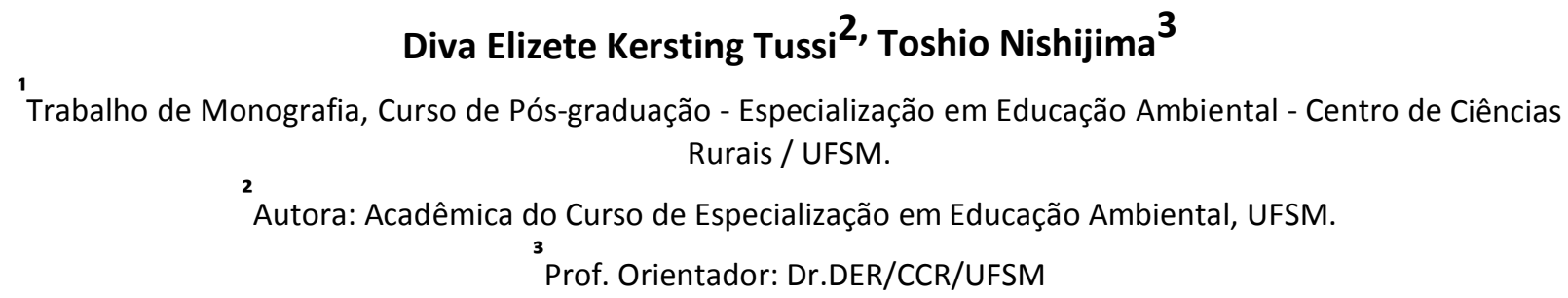

\section{RESUMO}

Neste trabalho realizou-se a verificação de conhecimentos e práticas ambientais através do Programa de pesquisa-intervenção educativa, dirigida aos alunos da 4a série do ensino público formal, da Escola Municipal Bom Pastor, no município de Panambi-RS. O estudo visou ampliar a consciência ambiental coletiva quanto ao valor e importância da água, assim como despertar interesse, reflexão e respeito pelo meio ambiente, através da promoção de uma trilha ecológica interpretativa, incentivando a preservação dos recursos naturais, em especial a água. Para tanto, utilizou-se da Educação Ambiental como instrumento principal e estratégico na sensibilização e preparação dos alunos quanto a necessidade do uso comedido e racional da água, salientando-se entre os meios para a sustentabilidade, a coleta da água da chuva. A pesquisa de intervençãoeducativa constituiu-se de três etapas: a efetivação de questionários sobre o conhecimento ambiental, a realização da trilha de percurso interpretativo com visitação a uma residência contendo um sistema de coleta da água da chuva e a distribuição e plantio de mudas de espécies de árvores nativas na escola. Os resultados obtidos evidenciaram que o estudo proposto contribuiu para qualificar e ampliar a consciência ambiental dos alunos, visto como um processo contínuo e permanente.

Palavras-chave: sensibilização; educação ambiental, consciência ambiental, uso racional, preservação da água.

\begin{abstract}
In this work there has to be knowledge and environmental practices through a program of research-educational intervention, directed at students in the 4th series of formal public education, the Municipal School Good Shepherd in the town of Panambi-RS. The study aimed at increasing environmental awareness conference about the value and importance of water as well as generate interest, reflection and respect for the environment through the promotion of an interpretive nature trail, encouraging the preservation of natural resources, especially water. To this end, we used the environmental education as the main and strategic awareness and prepare
\end{abstract}


students as the need for moderate and rational use of water, stressing, among the means of sustainability, collection of rainwater. Research-educational intervention consisted of three steps: the realization of questionnaires on environmental knowledge, the establishment of interpretive trail route with visitation to a house containing a system of collecting rainwater and the distribution and planting of seedlings species of native trees in the school. The results showed that the proposed study contributed to qualify and expand the environmental awareness of students, seen as a continuous and ongoing process.

Keywords: awareness, environmental education, environmental awareness, rational use, preservation of water.

\section{INTRODUÇÃO}

A humanidade está passando por uma das maiores crises ambientais já vistas nos últimos tempos, caracterizada pela fragilidade da natureza, colocando em risco a sobrevivência de todos os seres vivos. A crise derivada pela expansão tecnológica, o crescimento demográfico populacional e o estilo de vida humano individualista gera impactos ambientais de forma global e as nações viram-se envolvidas por um tema que não poderia mais ser ignorado, pois refletem direta ou indiretamente nas relações sociais, políticas e econômicas.

Tendo em vista a concepção de que o meio ambiente sempre foi considerado como fornecedor de recursos naturais em abundância, como se a natureza tivesse o poder da inesgotabilidade, desencadeou formas negativas de manejo pelo homem, resultando a poluição e degradação ambiental, merecendo especial atenção a escassez da água.

A água é um recurso natural e essencial para a vida na terra, fundamental à existência do homem, considerando que o próprio corpo humano é constituído por mais de $70 \%$ de água.

Segundo Grassi (2001) cerca de 97,5\% das águas superficiais consistem em água salgada, e 2,5\% restantes perfazem o total de água doce, dos quais $2 / 3$ estão armazenados nas geleiras e somente $0,77 \%$ de toda a água está disponível para o consumo humano. Mesmo o Brasil, que conta com cerca de $12 \%$ da água doce disponível no mundo, não deverá escapar da crise hídrica que está sendo prevista, Rebouças et al., (1999 apud GRASSI, 2001).

Machado (2004, apud SILVA et al., 2006) afirma que segundo hidrólogos e demógrafos o consumo humano de água doce duplica a cada 25 anos. O Banco Mundial informa que em 10 anos, $40 \%$ da população mundial não terão mais água suficiente para se sustentar $A$ crescente demanda por água tratada gera a necessidade de reuso planejado de água, o que remete a busca de estratégias e mecanismos para equilibrar e otimizar o consumo de água potável como solução racional e sustentável.

Esses acontecimentos remetem a urgência de medidas e mudanças de comportamento humano quanto a variável ambiental. Com este propósito, o presente trabalho foi realizado tendo por objetivo geral verificar conhecimentos e práticas ambientais através do Programa de pesquisa-intervenção educativa, dirigida aos alunos da 4a série do ensino público formal, da Escola Municipal Bom Pastor, no município de Panambi-RS, buscando ampliar a consciência ambiental coletiva quanto ao valor e importância da água. Constituiu-se por objetivos específicos:

- despertar interesse, reflexão e respeito pelo meio ambiente, através da promoção de uma 
trilha ecológica interpretativa, incentivando a preservação dos recursos naturais, em especial a água;

- sensibilizar para a necessidade do uso comedido e racional da água, ressaltando entre os meios para a sustentabilidade, a coleta da água da chuva.

Dentro desse contexto, busca-se soluções para o enfrentamento aos problemas hídricos da atualidade, utilizando-se a Educação Ambiental como ferramenta para desenvolver a competência dos educandos em pról da consciência ambiental cidadã mais crítica e ações responsáveis de gestão sustentável.

\section{REVISÃO BIBLIOGRÁFICA}

Com o desenvolvimento das formas produtivas a partir da 1 ạ Revolução Industrial no século XVIII, de acordo com Pires et al. (2008), intensificou-se gradativamente a intervenção humana no ambiente. Acelerou-se a maximização do uso excessivo dos recursos naturais e o ritmo de consumo, caracterizando o crescimento econômico a qualquer custo, gerando riscos e inquietações quanto ao futuro.

Para Capra (1995), a concepção de mundo na contemporaneidade está baseada na visão antropocêntrica. Essa teoria concebe o ser humano como a fonte de todos os valores, e atribui à natureza apenas um valor instrumental, ou de "uso servil".

Dessa forma, entende-se que o poder indiscriminado do homem abafa os valores da natureza, ou seja, o homem coloca-se como o centro do universo. Para Manifesto (2008 apud FElJÓ et al., 2008), essa linha de pensamento está em consonância com a teoria mecanicista cartesiana, que ignora os limites naturais do planeta do ponto de vista físico e biológico.

Entretanto, para Feijó et al. (2008), o desenvolvimento é um processo permanente de produção e/ou reprodução da qualidade de vida para a população em geral, contendo sustentabilidade ambiental, a equidade e a justiça social, tão importante quanto o crescimento econômico. "Quando o homem percebe que, apesar de estar condicionado a estruturas econômicas, não perdeu sua capacidade de criticá-las e de intervir junto a elas, abre espaço para transformá-la e transformar o mundo".(FEIJÓ et al., 2008, p 157).

No Brasil, $O$ interesse pelo meio ambiente tem se pronunciado desde a década de 60 com os primeiros passos do movimento ambientalista e evoluiu lentamente, ocorrendo as principais normas para a orientação das políticas públicas de proteção e qualidade do meio ambiente, como a Constituição Federal (CF) e a lei no. 6.938 em 31 de agosto de 1981.

A Constituição Federal promulgada em 1988, visa conter impactos da poluição sobre o meio ambiente e estabelece em seu artigo 225, que todos têm direito ao meio ambiente ecologicamente equilibrado, bem de uso comum do povo e essencial à sadia qualidade de vida, impondo-se ao Poder Público e à coletividade o dever de defendê-lo para as presentes e futuras gerações.

Apartir de 1988 os recursos hídricos passam a ser exclusivamente de domínio público e também "bens ambientais", e portanto "bens de uso comum do povo". Isso faz com que as águas se enquadrem, evidentemente, na proteção do enunciado do capitulo do art. 255 da CF

A Política Nacional de Recursos Hídricos (PNRH), Lei no. 9433/1997, define os seguintes princípios:

- A água é um bem de domínio público;

- A água é um recurso natural limitado, dotado de valor econômico;

- Em situação de escassez, o uso prioritário dos recursos hídricos é o consumo humano e a dessedentação dos animais; 
- A gestão dos recursos hídricos deve proporcionar o uso múltiplo das águas;

O desafio de minimizar os impactos negativos resultantes das atividades humanas e manter-se o equilibrio ambiental remete a adoção da noção do desenvolvimento sustentável, o qual respeita e funciona dentro dos limites da natureza. Este processo necessita da modificação de alguns estilos de vida e dos métodos de desenvolvimentodas nações, onde a tecnologia deverá se preocupar com as outras pessoas, com o ecossistema e com as gerações futuras. Com isso, deve-se chegar a uma partilha justa do uso e da conservação dos recursos naturais, porque o prejuízo de umas das partes pode afetar o todo, da mesma forma que a sobrevivência das espécies dependa de outras, o uso indiscriminado ameaçará todas as espécies.

Nesse contexto:

Desenvolvimento Sustentável é aquele que atende às necessidades do presente sem comprometer a possibilidade de as gerações atenderem às suas próprias necessidades, (ALMEIDA et al., 1993 apud FEIJÓ et al., 2008, p.97).

De acordo com Cabrera (2008), sustentabilidade é um conceito sistêmico, ou seja, ele correlaciona e integra de forma organizada os aspectos econômicos, sociais, culturais e ambientais da sociedade. A palavra-chave é continuidade, como essas vertentes podem se manter em equilíbrio ao longo do tempo.

Para orientação e fiscalização das ações das atividades econômicas do homem foi instituído pela Política Nacional do Meio Ambiente (PNMA), lei 6938/81, instrumentos que definem normas e padrões de qualidade ambiental.

Entre os princípios da Política do Meio Ambiente destaca-se o art. 2o, definindo a educação ambiental a todos os níveis de ensino, inclusive a educação da comunidade, objetivando capacitá-la para participação ativa na defesa do meio ambiente. A sociedade civil efetivando o direito da informação estará habilitada a decidir que tipo de cidade/planeta pretende construir para essa e futuras gerações.

Entende-se que a Educação Ambiental é "mais um instrumento de mediação necessária entre culturas, comportamentos diferenciados e interesses de grupos sociais para a construção das mudanças que se pretende realizar" (TAMAIO, 2000 apud FEIJÓ et al., 2008 p.154).

Segundo Mendonça (2009), no Brasil a Educação Ambiental assume uma perspectiva mais abrangente, não restringindo seu olhar à proteção e uso sustentável de recursos naturais, mas incorporando fortemente a proposta de construção de sociedades sustentáveis. Mais do que um segmento da Educação, a Educação em sua complexidade e completude.

Cumpre observar que de acordo com a Lei no. 9.795/95, a Educação Ambiental consiste em processos através do qual, o indivíduo e a comunidade constroem valores sociais, conhecimentos, atitudes, competências voltadas para a conservação do meio ambiente, indispensável à qualidade de vida e sua manutenção.

Tem-se que:

É através da educação, entendida de uma forma ampla, como educação para a vida, que o ser humano desenvolve um amor por si mesmo, pelo outro e pelo ambiente em que se encontra. A Educação Ambiental é, talvez, a melhor porta de entrada para um pensamento tão amplo, uma vez que questiona valores, os modelos vigentes, propõe relacionamentos mais harmônicos entre todos os seres vivos do planeta. (PÁDUA, 1997, apud GUIMARÃES 2006, p.8). 
Entre as formas de se efetivar a Educação Ambiental destaca-se as trilhas de interpretação. A trilha interpretativa é um instrumento metodológico que pode ser utilizada tanto no ensino da Educação Ambiental formal como informal, independente da faixa etária. A trilha envolve percursos interpretativos orientados objetivando integração sócio-ambiental, o conhecimento científico da natureza e a mudança de comportamento do homem ao seu entorno. Ela pode ser feita em qualquer espaço físico, inclusive urbano, com diferentes contextos, uma vez que a noção de que tudo é ambiente, por si só, já permite a visualização da interdisciplinaridade.

A trilha condiciona o aluno na busca da análise de significados e características do ambiente por meios de elementos naturais, oferece também situações para exercitar valores cognitivos, cria expectativas, suscita questionamentos e despertam novos conhecimentos. Dessa forma desenvolve o senso e responsabilidade de exploração racional dos recursos naturais, assim como a conservação e preservação

\footnotetext{
A interpretação da natureza no contexto de uma trilha ecológica é atividade educativa que tem como objetivo a revelação de significados, relações ou fenômenos naturais por intermédio de experiências práticas e meios interpretativos, ao invés de simples comunicação de fatos e datas. (DIAS,

2001 apud GUIMARÃES, 2006, p.11).
}

De acordo com Merck (2009), o planejamento de uma trilha interpretativa deve considerar o levantamento físico e topográfico da área, a escolha do grupo-alvo, a infra- estrutura física, cronograma, material de apoio, como folder informativo e roteiro que levem a despertar reflexão e gerar recursos de avaliação.

\section{METODOLOGIA}

O programa de pesquisa intervenção-educativa foi efetivado no âmbito do ensino formal público, tendo como grupo-alvo, alunos da 4a série, matriculados na Escola Municipal Bom Pastor, localizada no bairro Kuhn no município de Panambi (RS).

Como instrumento metodológico, foi desenvolvida uma trilha interpretativa ambiental, com percurso orientado, objetivando a integração sócio-ambiental, e a sensibilização dos alunos especialmente a respeito dos problemas ambientais da comunidade, despertando neles, a vontade de construir o próprio conhecimento e buscar soluções para os seus questionamentos.

Para a coleta de dados foi efetivada a aplicação de três questionários, sendo que os alunos tiveram a liberdade de assinalar mais de uma resposta, portanto ultrapassando o somatório dos $100 \%$ dos participantes. O estudo caracterizou uma pesquisa quantitativa dos resultados, complementadas com as demais informações obtidas através de diálogos informais com aluno, professor e direção da escola.

Foi utilizado como recurso e material de registro, uma máquina fotográfica, um folder explicativo, rolo de barbante, fitas coloridas, mudas de árvores nativas, ferramentas para plantio (enxada e pá), balde com água e material individual do aluno, adequado ao evento (boné, protetor solar, água e outros).

O estudo efetivado constituiu-se por 3 etapas, realizadas em 3 oportunidades e dias determinados, agendado pela coordenação da escola e seguidas de acordo com os seguintes passos: 


\section{Primeira etapa}

O levantamento de dados para a efetivação do estudo seguiu a respectiva ordem:

1ㅇ - Apresentação do programa e proposta de estudo para a direção e respectiva turma participante do estudo, desenvolvendo um diálogo informal de integração, aproximação e aceitação.

2ㅇ - Aplicação de um questionário social (Anexo 1) visando à coleta de dados para configurar o perfil sócio econômico da turma em foco.

3o - Aplicação de um questionário pré trilha interpretativa (Anexo 2) buscando inicialmente diagnosticar o grau de percepção da realidade ambiental do aluno, seu conhecimento e práticas vivenciadas por ele.

\section{Segunda etapa}

4ㅇ - Apresentação e distribuição de um folder (Anexo 4) como material e recurso de apoio do percurso interpretativo, contendo roteiro e dados informativos, assim como abordagem de questões especificas, que despertassem interesse, reflexão e questionamentos pelos alunos.

5ㅇ - Efetivação da Trilha interpretativa percorrida a pé, sendo composta inicialmente por espaços urbanos, com seqüência a espaços naturais se efetivando no Parque Municipal Rudolfo Arno Goldhardt de Panambi, situado na Avenida Konrad Adenauer, costeando as margens do rio Fiúza, próximo ao centro da cidade, numa pista já existente para caminhadas em meio à mata nativa.

60 - Parada para reflexão especial, onde foi realizada a técnica da Teia de Aranha (Anexo5) cuja atividade gera uma simulação de rede. O exercício visa à compreensão da participação e interdependência dos seres vivos, assim como a interação com demais elementos do meio ambiente, tendo seus pontos constituídos pelos próprios alunos, interligados com o barbante, formando uma espécie de teia de aranha. Também foi usada uma técnica similar, caracterizando o efeito dominó, refletindo as conexões e interdependência entre os problemas ambientais, causas e conseqüências.

70 - No final da trilha interpretativa, já em espaço urbano, foi feito uma visitação e contemplação a uma residência, onde os alunos puderam ter oportunidade de visualizar a instalação hidráulica de um sistema de coleta da água da chuva (Anexo 6) e conhecer informações específicas dessa técnica de manejo sustentável e suas vantagens.

8 - Finalizando a programação dessa etapa, de volta a escola, os alunos efetivaram o plantio de uma muda de árvore de espécie nativa no jardim da escola. Foi "combinado" entre os alunos um compromisso de respeito, responsabilidade e cuidados com o meio ambiente e em economia da água. Esse comprometimento foi selado com uma fita amarrada no braço, como lembrete à prática de novos hábitos e valores, encerrando-se o momento com a distribuição de mudas de árvores nativas para cada aluno fazer o seu próprio cultivo em casa. 


\section{Terceira etapa}

9o - Foi promovido um diálogo, refletindo as novas experiências oportunizadas pela trilha ambiental orientada e outras atividades realizadas na escola.

10 - Aplicação de um questionário avaliação pós-trilha (Anexo 7), visando nova coleta de dados, verificando a ampliação do conhecimento ambiental pelo aluno, mediante as atividades desenvolvidas no dia 22/09/2009, possibilitando o encerramento do estudo proposto.

\section{RESULTADO E DISCUSSÕES}

Mediante os resultados do questionário sócial e demais informações da direção escolar, traçouse o perfil sócioecnômico dos participantes do estudo, caracterizando-se um grupo de alunos homogêneo, em sua maioria da classe média. Considerou-se as condições habitacionais, constituição familiar e demais fatores, sendo que tais aspectos, não refletiram entre os participantes em geral, diferenças quanto ao grau de conhecimento do ambiente.

Verificou-se mediante as respostas do questionário de conhecimento do meio ambiente, que os alunos nessa faixa etária, já possuem certo grau de percepção ambiental. Após conversa informal com os alunos, percebeu-se que para a maioria deles, predomina a noção de meio ambiente como espaço natural ou a natureza criada por Deus.

Destacou-se a necessidade de aprofundar e associar a noção de que o homem também faz parte dessa natureza, se relaciona e faz conexões com todo o ecossistema através de suas ações e por isso é o principal responsável pela sua preservação.

A escola tem desenvolvido conteúdos que abrangem a temática ambiental, especialmente na matéria de Ciências, orientando os alunos para preservar o Planeta para as futuras gerações e oportunizam essa aprendizagem através do estudo praticado a respeito da seleção de resíduos. Entretanto é preciso desenvolver mais profundamente a visão de que não basta somente selecionar o lixo, é preciso reduzir o consumo e optar por produtos que ofereçam menos riscos de agressão ao ambiente.

A escola incentiva os alunos a economizar a água, por outro lado, falta maior esclarecimento quanto à proteção das nascentes e quanto à origem da poluição, que seria facilitado com a intensificação da interdisciplinaridade.

Ocorreu a realização da trilha ecológica (Anexo 3), considerada de curta distância e configurada em forma linear, comum e simples, apresentando facilidade de acesso, pois já existia o percurso trilhado, sendo que todos os alunos participaram sem dificuldades.

Durante a realização da trilha foi possível aproveitar todas as observações, sensações, interesses e indagações despertados por parte dos alunos, sendo estimulados e também questionados a respeito de tudo o que visualizavam.

Diversos temas foram discutidos, entre os quais destacou-se a sensação das temperaturas mais elevadas no espaço urbano, comparado ao micro clima ameno da mata ciliar, nas margens do Rio Fiúza. Houve referência sobre o relevo acidentado e espaço pavimentado, o que levou a análise do sistema de escoamento das águas das chuvas, esclarecendo os motivos das enchentes nesses locais.

Seguindo o percurso, salientou-se a destinação inadequada dos resíduos sólidos, em especial a quantidade de sacolas plásticas penduradas nos galhos das árvores sobre o rio, assim como a incidência da erosão dos barrancos e assoreamento do leito do rio. 
Os alunos identificaram o escoamento de esgotos no corpo da água, e se ressaltou a necessidade de rede de esgoto na cidade. Comentou-se a respeito do alto índice de coliformes fecais nas águas do Fiúza, (16 vezes a mais que o aceitável).

Verificou-se a construção das casas muito próximas às margens do rio, devido a construção desordenada, especialmente nos espaços que deveriam ser destinados a áreas verdes, e consequentemente a redução da quantidade e qualidade da água, e as prováveis poluições, (agrícolas, domésticas, industriais).

Salientaram-se a importância, valor e utilidade da água para se manter a vida, e o grande desperdício. Debateu-se sobre a existência de peixes, a possível contaminação e as doenças causadas ao homem pela cadeia alimentar e pela própria água quando não tratada, assim como a importância da mata ciliar na proteção dos mananciais.

Os alunos demonstraram interesse para o assunto do desmatamento e também quanto ao consumo abusado dos recursos naturais. Questionou-se sobre a necessidade de buscar o equilíbrio entre o consumo e a recuperação da natureza. Eles listaram diversos tipos de árvores existentes no parque, as quais já possuíam placas de identificação e perguntaram sobre as espécies de árvores nativas mais aconselháveis para a recuperação da fauna. Enfim, foi uma aventura realizada de forma animada, instrutiva e prazerosa.

Após o passeio no parque se fez a visitação a uma residência com instalação de um sistema de coleta da água da chuva, sendo que o proprietário se fez presente nesse momento, explicando as vantagens dessa forma de manejo. O proprietário divulgou aos alunos que direcionava o uso da água para os serviços de limpeza da casa, lavagem de roupa, rega da horta e jardim e principalmente para a sua atividade de trabalho que envolvia chapeamento de carro.

Os alunos mostraram-se interessados fazendo perguntas quanto a outras formas e possibilidades de instalações do reservatório e funcionamento desse sistema e principalmente quanto à economia da água potável especialmente em períodos de seca.

Alguns alunos sugeriram que o ideal seria um reservatório maior e que levariam para os pais estas idéias, sendo esclarecido que a dimensão do telhado da casa é importante para a quantidade de água que se quer captar, dependendo da finalidade do seu uso.

$\mathrm{Na}$ atividade de plantio de mudas nativas na escola, foi ressaltada a importância de se criar áreas verdes e se manter espaços permeáveis para a percolação da água da chuva, dessa forma minimizando as enchentes que é um problema na cidade.

Seguindo a programação, aplicou-se o último questionário, pós trilha, destacando-se alguns resultados mediante as representações gráficas que se seguem:

De acordo com o gráfico (Figura 4.13) e o que o aluno acredita ser importante para o meio ambiente, verificou-se que $100 \%$ dos alunos optaram por assinalar mais de uma resposta. Constatou-se a incidência de $100 \%$ nas respostas das letras "a e da letra b", confirmando a urgência de que todas as pessoas precisam preservar os rios e economizar a água para viabilizar a perpetuação da vida. Isso significa dizer que é necessário romper com os atuais padrões de consumo exagerado e desperdícios, remetendo o próprio aluno a divulgar a sua aprendizagem ao perceber a importância de educar toda a coletividade para a proteção ambiental. 
TUSSI \& NISHIJIMA, vol.(4), nº, p. 758-772, 2011.

Monografias Ambientais

(e-ISSN: 2236-1308)

REMOA

120

100

80

60

40

20

0

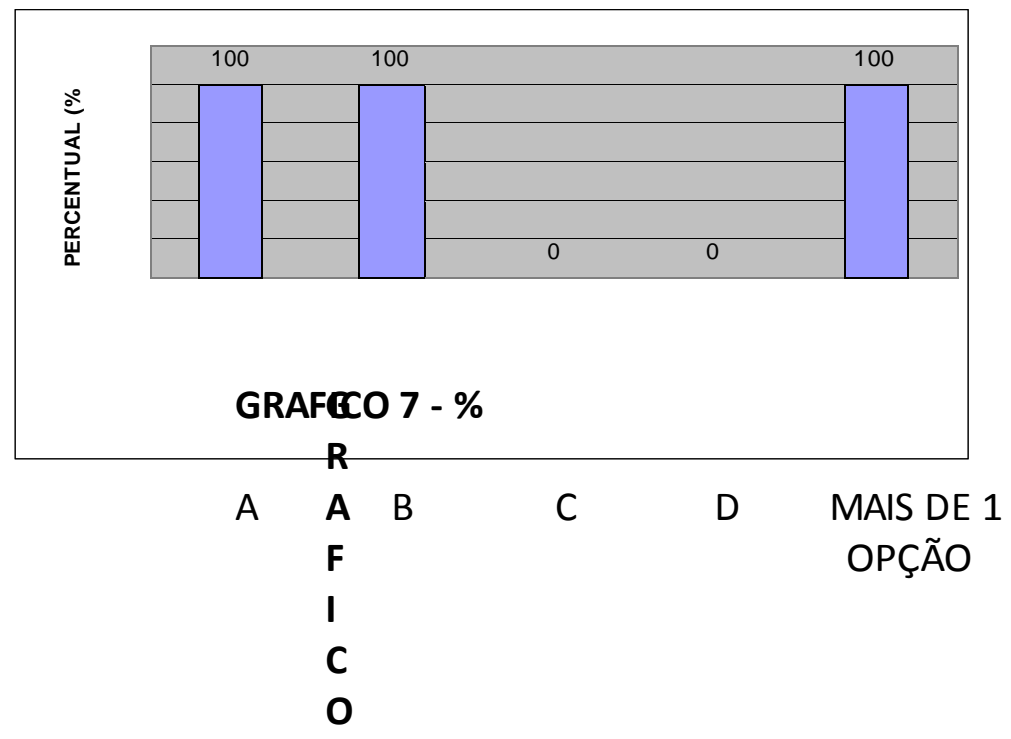

7

$\%$

Figura 4.13 - Após a realização da trilha interpretativa você acredita que é muito importante: Resposta: a) Preservar o meio ambiente, pois só assim teremos as condições necessárias para viver; b) Pedir aos pais, vizinhos e conhecidos que ajudem a preservar os rios e que economizem a água, pois ela é essencial à vida; c) Aumentar a quantidade de compras, mesmo que não precise, pois tem tantas promoções boas de vendas; c) Todas as respostas estão certas. Pesquisa realizada com os alunos da 4ạ série da Escola Municipal Bom Pastor - Panambi (RS) em 23/092009.

Em relação ao questionamento "de que forma você pode economizar água potável?" (Figura 4.15), $100 \%$ dos alunos optaram por mais de uma opção, sendo $100 \%$ nas respostas a, b e c. Significa que os alunos adquiriram conhecimento quanto às atitudes que precisam adotar para a economia e manejo sustentável da água, desde o reuso e especialmente na coleta da água da chuva, que é gratuita. Oportuno se torna dizer, quanto à necessidade constante de incentivo entre as pessoas, visando à participação no cumprimento dessa meta, haja vista que a água como fonte de vida é um bem natural publico, e todos têm o dever e a responsabilidade na sua preservação. 
TUSSI \& NISHIJIMA, vol.(4), n4, p. 758-772, 2011.

Monografias Ambientais

(e-ISSN: 2236-1308)

REMOA

120

100

80

60

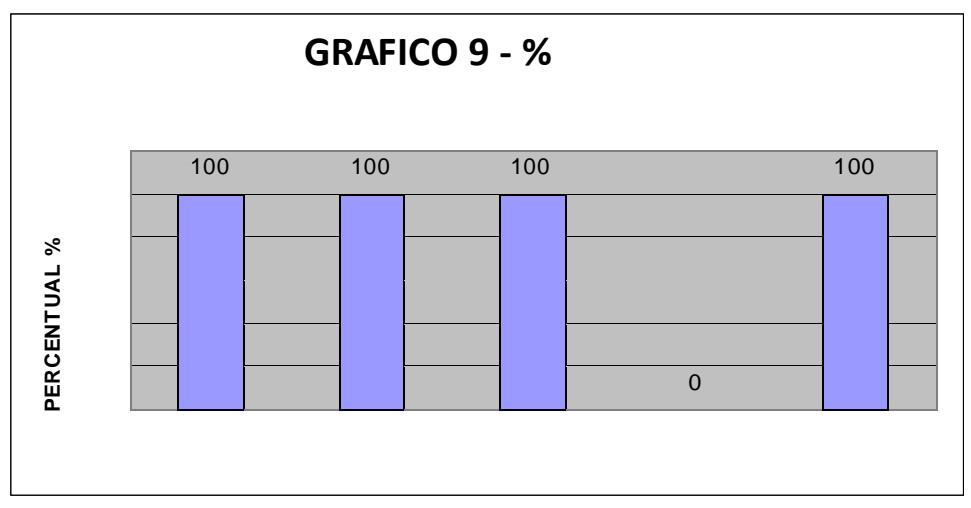

40

20

A

B

C

D MAIS DE 1

0

OPÇÃO

Figura 4.15 - De que forma você pode economizar água potável? Sendo: a) Tomando banho em menor tempo possível; b) Reutilizando a água da máquina de lavar roupa para lavar calçadas; c) Coletando a água da chuva em reservatórios (caixa da água), principalmente para serviços de limpeza e rega de hortas e jardins; d) Todas as respostas estão erradas. Pesquisa realizada com os alunos da 4a série da Escola Municipal Bom Pastor Panambi (RS) em 23/092009

Nessa questão "é importante cuidar e preservar a água e manter o meio ambiente saudável e equilibrado, por isso é preciso:" (Figura 4.16), 100\% dos alunos optaram por mais de uma opção, sendo $100 \%$ nas letras a e b concomitantemente, significando sensibilização pela causa da defesa ambiental, proteção as nascentes e poupança da água. Subtendem que o cuidado com a água é também um cuidado com a vida. Essa e demais questões remetem o aluno a pensar, a se posicionar e se relacionar com o meio ambiente de forma respeitosa, ampliando a sua visão de cultivo aos demais seres vivos. 
TUSSI \& NISHIJIMA, vol.(4), nº, p. 758-772, 2011.

Monografias Ambientais

(e-ISSN: 2236-1308)

REMOA

120

100

80

60

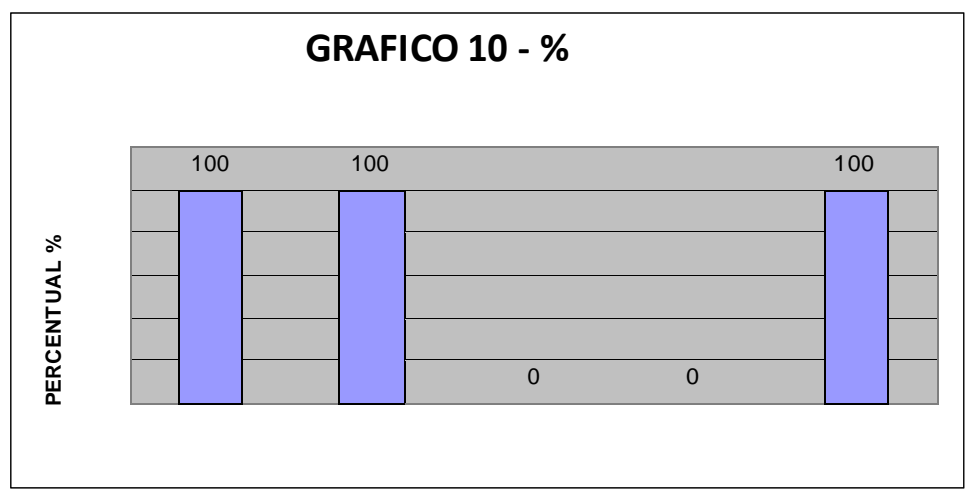

40

20

A

B

C

D

MAIS DE 1

0

OPÇÃO

Figura 4.16 - É importante cuidar e preservar a água e manter o meio ambiente saudável e equilibrado, por isso é preciso: Sendo: a) Reflorestar as margens dos rios e nascentes (mata ciliar), evitando o desmoronamento dos barrancos (erosão), usando mudas nativas como, pitangueiras, cerejeira, guabiroba e outras, gerando alimento e abrigo para os animais e aumentando a qualidade e quantidade da água; b)

Adotar novos hábitos, poupando água, energia elétrica, gás, combustível, alimentos, embalagens e outros; c) A água pode ser usada a vontade, pois a escassez é temporária e nossa cidade sempre terá água; d) Todas as respostas estão certas. Pesquisa realizada com os alunos da 4á série da Escola Municipal Bom Pastor - Panambi (RS) em 23/09/2009.

De acordo com a apuração quanto às maiores causas da degradação ambiental (Figura 4.17), verificou-se que $100 \%$ dos alunos optaram pelas letras a, b e c. Todos marcaram mais de uma opção. Essa incidência reflete a ampliação do conhecimento relacionado às causas do desequilíbrio ambiental, frente ao aumento populacional, aumento de consumo, a posição de superioridade do homem utilizando a natureza somente como fornecedora de matéria prima.

Salienta-se também a falta da formação de valores consistentes, menos transitórios, os quais norteiam as pessoas a viverem de forma digna. Cumpre observar, referente a esta questão, é que o desafio maior é atuar sobre as causas do desequilíbrio ambiental, pois isso exige um novo jeito de se compreender o mundo e de se relacionar enquanto pessoa com a natureza, com os seres vivos e o entorno.

Nesse sentido os alunos sentem o dever de fazer a sua parte, habilitados gradativamente pelas ferramentas da Educação Ambiental, mas torna-se importante vincular o gerenciamento ambiental adequado aos outros segmentos da sociedade, para que siga-se o mesmo rumo, pois os alunos enfrentarão contradições e indiferenças e precisam perceber que existe a intenção para mudanças e transformações desse estilo de vida. 
TUSSI \& NISHIJIMA, vol.(4), n4, p. 758-772, 2011. Monografias Ambientais

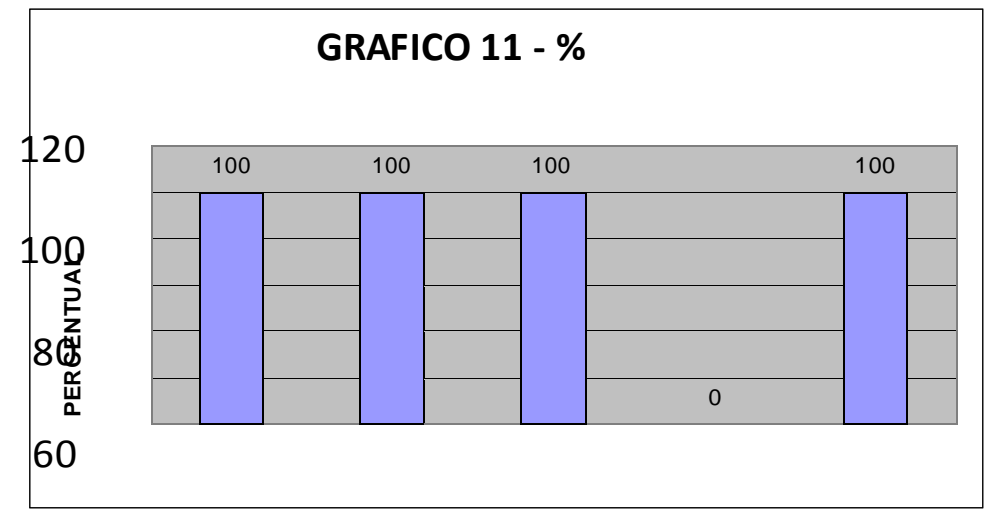

40

20

0

A $\quad$ B $\quad$ C $\quad$ D $\quad$ MAIS DE 1

OPÇÃO

Figura 4.17 - As maiores causas dos problemas do desequilíbrio ambiental: Sendo: a) O aumento da população e o consumo abusado dos recursos naturais; b) O homem com suas invenções, se sente o dono do mundo, desrespeita a natureza, causando prejuízos a qualidade de vida de todos os seres vivos; c) O homem tornou-se muito materialista e individualista, só pensa em "ter" lucro a qualquer custo, mesmo que prejudique o ambiente e as pessoas, esquecendo os valores de solidariedade, honestidade, dignidade, amor e respeito; d) Todas as respostas estão erradas. Pesquisa realizada com os alunos da 4ạ série da Escola Municipal Bom Pastor - Panambi (RS) em 23/09/2009.

Frente a proposição, "precisamos seguir um novo Plano de vida, contendo soluções para recuperar o meio ambiente e construir um mundo melhor, sendo preciso:" (Figura 4.19), há ocorrência de $100 \%$ na múltipla escolha, assim como $100 \%$ dos alunos optando pelas respostas a, b, d, sendo que $92 \%$ marcaram a letra $c$. Esse resultado reflete que os alunos sabem que há a necessidade de mudanças e que precisam adotar novas atitudes e agir em prol desse novo plano de ação para que se alcance a salvação do Planeta.

Nessa linha de pensamento e em consonância com as outras questões, os alunos demonstraram perceber que todos os cidadão são co-responsáveis pelo cuidado com a natureza e bens produzidos, assim como esses bens deveriam beneficiar a todas as pessoas em iguais condições. Esses alunos já subiram mais um degrau na escala de crescimento da percepção ambiental, o que ajuda na compreensão da vida.

Entretanto, a vida é o resultado de múltiplas e complexas interações que desencadeiase em redes, que vão atribuindo significados para nossas relações. Nesse sentido o aprofundamento do entendimento por parte dos alunos, de como poderia ocorrer todas essas mudanças e transformações a um novo paradigma, exige superação de etapas e maior conhecimento, tempo e amadurecimento. Esse processo deve ser gradativo e contínuo, baseado na interdisciplinaridade de idéias e ações, facilitando o relacionamento entre a sociedade e a natureza, e desse modo, alicerçando a visão desse aluno em um cidadão 
crítico, que saberá reivindicar por implementações de políticas que ataquem a raiz do problema e não maquiam as soluções.

As mudanças para um novo plano de vida, precisam ser norteadas pela solidariedade e sustentabilidade, contando com a participação e esforços em todas as escalas da sociedade, com vista ao crescente melhoramento ambiental e da qualidade de vida humana, envolvendo também os valores de dignidade e justiça.

\section{GRAFICO 13 - \%}

20

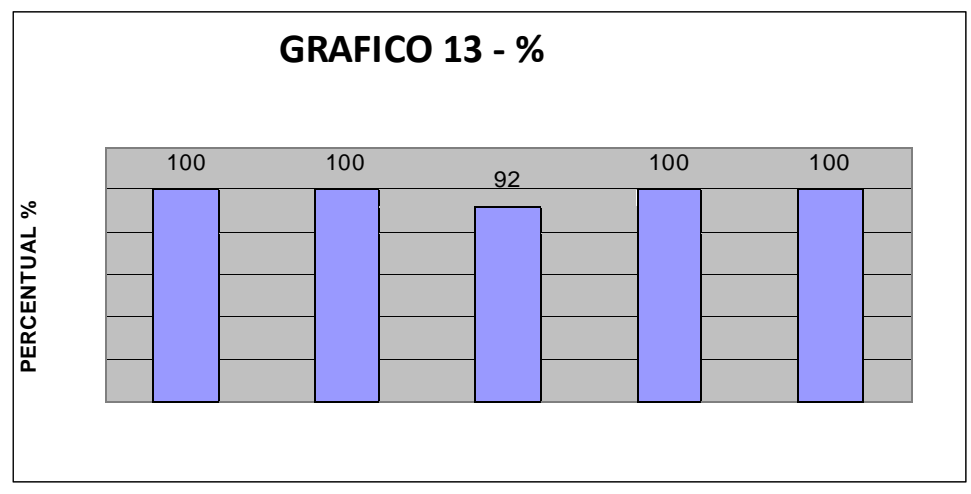

0
A
B
C
D MAIS DE 1
OPÇÃO

Figura 4.19 - Precisamos seguir um novo "Plano de vida", contendo soluções para recuperar o meio ambiente e construir um mundo melhor, sendo preciso: Sendo: a) Adquirir novas atitudes e cuidados com o meio ambiente, pois uma boa ação pode melhorar a vida de todos. b) Que as empresas e toda a comunidade se preocupem com o tratamento dos esgotos (de banheiros, cozinha, e águas com produtos químicos) evitando a contaminação dos rios; c) Que a água na indústria, na agricultura e residências seja usada de forma racional, econômica, coletada, tratada, e reutilizada; d) Que toda a população tenha uma vida mais digna, que diminua a distância entre os ricos e pobres e que não haja mais fome e que todos tenham escola e o povo saiba escolher políticos honestos. Pesquisa realizada com os alunos da 4ạ série da Escola Municipal Bom Pastor - Panambi (RS) em 23/0912009.

Após as apurações e análise do questionário de aprendizagem pós-trilha, é oportuno mencionar que de acordo com Freire (1990), existem graus de educação, mas estes não são absolutos, e o saber se faz através de uma superação constante, sendo que a educação tem um caráter permanente. Nesse contexto, compreende-se que o processo de aprendizagem é contínuo e efetiva-se a vida toda, e como afirma Freire, "a educação é uma resposta da finitude da infinitude".

Cumpre observar também que a Educação Ambiental para oportunizar competência e ser eficiente precisa inovar em metodologia, sendo que já se reciclou a fórmula do CHÁ (Conhecimento, Habilidade e Atitude), acompanhadas de "Saber, Poder e Querer", que segundo McClelland (1970, apud MUSSAK, 2009 p. 114), essa equação é um produto, se um dos três for nulo, o resultado final será competência zero, sendo que para o novo século, transformou-se o CHÁ para CHAVE. Nesse contexto, é a chave da competência ampliada, é o acréscimo de duas letras, o "V" de Valores e o "E" de Entorno. 
Deve-se ter presente que, uma sociedade digna, preocupada com o social e responsável com o futuro, precisa resgatar valores. De que adianta produzir sem sustentabilidade, competir sem ética e conquistar sem moral? Nessa linha, o aluno que resgatar estes valores (tidos como atemporais), deve incorporar, intensificar e ser fiel a eles, e dessa forma, mudará de postura, se tornará um cidadão em um ambiente onde a competência encontra condições para ser exercida, com gerenciamento do meio ambiente inspirados no principio do tripé da sustentabilidade, racionalização e responsabilidade.

De acordo com o referencial teórico e segundo Capra (1995) para tecer uma visão abrangente da realidade é preciso ligar todos os nós e fazer conexões das relações do sistema no qual estamos inseridos. Esse sistema reflete uma rede, sendo que se houver uma perda de uma linha de conexão, por não estarem bem "amarradas", pode causar um rompimento fiel dessa realidade.

Denota-se pelas interpretações dos resultados, que após o aluno ter refletido sobre o princípio básico de respeito ao próximo e a natureza, primordial para a sustentabilidade e continuidade da vida na terra, estará sujeito a novos relacionamentos, posicionamentos e valores éticos, contribuindo para o fortalecimento do caráter e atitudes de preservação e uso racional dos recursos naturais.

O aluno demonstrou no desempenho final de suas posturas, através de suas opiniões críticas a respeito da problemática do ambiente, o quanto é falso a concepção de que a água é um recurso inesgotável e que há urgência em poupar a água, proteger suas fontes, evitar a sua contaminação. São metas ambiciosas que os alunos se propuseram a buscar para ajudar na recuperação do equilíbrio ecológico planetário e a si mesmo, tornando-se mais solidários também com as próximas gerações.

Ressalta-se também a necessidade da substituição do desenvolvimento econômico a qualquer custo pelo desenvolvimento sustentável, justo e solidário, onde a economia deve estar a serviço da dimensão social, a tecnologia não deve degradar o meio ambiente e a construção de um novo cenário onde todos os indivíduos tenham igual acesso aos meios de vida.

\section{CONSIDERAÇÕES FINAIS}

A pesquisa de intervenção educativa contribuiu para a sensibilização e ampliação da consciência ambiental coletiva quanto ao valor, importância, uso racional e manejo adequado da água.

Verificou-se que o processo de conscientização deverá ser buscado gradativamente, em longo prazo, haja vista que a conscientização ambiental propriamente dita, exige reflexão e habilidade para a ação, ou seja, teoria e prática. Processo que requer, acompanhado, monitorado, reforço, apoio e observação da freqüência e continuidade da prática, o que remete o aluno a abandonar a zona de conforto e assimilar novo estilo de vida e valores, concretizando-se a mudança de comportamento.

Recomenda-se que para agilizar o processo de conscientização seria positivo que a escola/professores/alunos articulem projetos em parcerias com associações de bairros, empresas e outras instituições, buscando desenvolver programas ambientais, viabilizando acesso a essas aprendizagens, formando uma frente harmônica de busca a causa, segregando 
esforços em escalas crescentes.

Na visão de mundo moderno, a mudança de postura já não é mais uma opção, mas sim uma imposição, sendo que a Educação Ambiental pode contribuir na formação de cidadãos competentes, atentos para que os resultados não sejam obtidos a qualquer custo, atropelando as pessoas e prejudicando o ambiente, mas formando uma nova visão de mundo, constituído por pessoas que vivem com dignidade e justiça, cada um fazendo a sua parte.

\section{REFERÊNCIAS BIBLIOGRÁFICAS}

CABRERA, L. É tudo uma questão de princípios, ed. 126, São Paulo, Ed. Abril, Dez. 2008 (Revista Você).

CAPRA, F. Uma nova compreensão científica dos sistemas vivos, São Paulo Berkeley, Editora Cultrix, 1995

FREIRE, P. Educação e Mudança, 16a ed., São Paulo, Editora Paz e Terra S/A, 1990.

FEIJÓ, C. (org.) et al. Gestão Ambiental: A sociedade, Meio Ambiente e Cidadania. Tópicos Especiais em Educação Ambiental: Mód. 2, Londrina-PR, Unopar, 2008.

GRASSI, M. Água no Planeta Terra: Cadernos Temáticos de Quimica Nova na Escola, Londrina-PR, [sn], 2001.

GUIMARÃES, V. Uso de Trilha Interpretativa na Educação Ambiental: Uma proposta para o município de Rosário da Limeira - MG, 2006. (Curso de Geografia ) - Faculdade Federal de Juiz de Fora. MAGALHÃES, H. Advogados Associados. 0 que é Direito Ambiental . Disponível em: <www.direitoambiental.adv.br/ambiental.qps/Ref/PAIA6S9TNQ - 38k> Acesso 29 de abril de 2009

MENDOÇA, R. Nova Escola: O educador ambiental ensina por suas atitudes. Disponível em: http://pt.wikipedia.org/wiki/Educa\%C3\%A7\%C3\%A3o ambiental>. Acesso em 25 de julho de 2009.

MERCK, A. Trilhas Ecológicas, Santa Maria, [sn], 2009.(Cartilha)

MUSSAK, E. A crise de percepção, ed. 126, Ed. Abril, São Paulo, Dez. 2008. (Revista Você).

Como anda o seu salário, ed. 135, São Paulo, Ed. Abril, Set. 2009. (Revista Você)

PIRES, E. (org.), et al Gestão de recursos hídricos: Gestão Ambiental 3, São Paulo, Pearson Education, 2009.

SILVA, MANZANARES, MOTA, Viabilidade de reutilização de água para vasos sanitários. ed. 2, Agos., 2006 (Revista Ciências do Ambiente On-.Line)

TROLEIS, A. Cuidado com a água e com a vida. Jornal Mundo Jovem no 313, Fev., Porto Alegre - RS, PUC/, 2001. 